American Journal of Agricultural and Biological Sciences 7 (2): 194-200, 2012

ISSN 1557-4989

(C) 2012 Science Publications

\title{
Effectiveness of Agricultural Extension Activities
}

\author{
Ali AL-Sharafat, Mohammad Altarawneh and Ebraheem Altahat \\ Department of Agricultural Economics and Extension, \\ Faculty of Agriculture, Jerash University, Jerash, 26150, Jordan
}

\begin{abstract}
Problem statement: Jordan's agricultural extension service is seriously under-staffed and its effectiveness is consequently compromised. Reservations are being expressed about the performance and capability of the agricultural extension system in Jordan. The performance of this sector has been disappointing and has failed to transfer agricultural technology to the farmers. The main objective of this study is to assess the effectiveness of Jordan's agricultural extension services. Approach: The effect of extension services on olive productivity in the study area was investigated. A total number of 60 olive producers were selected to be interviewed for this study. This number was enough to achieve the study objectives. The interviewed producers were distributed almost equally within olive production locations in the study area. The sample obtained through the simple random sampling technique. The two groups had been chosen and distributed randomly into an experimental group (30 farmers; 10 for each source of extension service) and control group (30 farmers). The experimental group received extension services and the control group received no extension services. Two interview-cum-structured questionnaires were designed and used to collect information and data for this study. The first instrument was designed for farmers who received extension services and the second from farmers who received no extension services. Another questionnaire was designed for administrators of extension organizations concerned with providing extension services to farmers. To find the differences that may exist between two studied groups, One Way Analysis of Variance (ANOVA), t-test and LSD test via Statistical Package for Social Sciences software (SPSS) were used. The average net profit obtained from an area of one dynamo of olive farm was the main item to be considered in determining the effectiveness of agricultural extension activities. Results and Conclusion: The results of the study revealed that the net profit of farmers who received extension services is almost the same as those who do not receive any extension services. The provided extension services made no difference in the achievement of farmers regarding their production and consequently their net profits. The three main investigated sources of extension services provide inadequate and less effective extension services. To overcome most of the obstacles facing extension programs in Jordan the government should impart extensive in-service agricultural trainings to train the extension personnel to cope with the growing needs of farmers. The establishment of field demonstration sites, pilot sites on farmers' fields around the demonstrations is another important issues to be covered.
\end{abstract}

Key words: Effectiveness, olive, agricultural extension system, net profit, agricultural extension providers, Statistical Package for Social Sciences software (SPSS)

\section{INTRODUCTION}

The extension isn't merely occupying a bridge position but facilitates to improve the efficiency and effectiveness of both the farmer and the research, to facilitate transfer of agricultural technologies among the farmers (Rivera et al., 1997). Extension starts with knowledge management and ends up with human enrichment. Agricultural extension by its nature has an important role in promoting the adoption of new technologies and innovations (Jamilah et al., 2010). Agricultural extension brings about changes through education and communication in farmers attitude, knowledge and skills. The role of agricultural extension involves dissemination of information, building capacity of farmers through the use of a variety of communication methods and help farmers make informed decisions (Sinkaiye, 2005).

The extension services can play a crucial role in providing information on sustainable agricultural

Corresponding Author: Ali AL-Sharafat, Department of Agricultural Economics and Extension, Faculty of Agriculture, Jerash University, Jerash, 26150, Jordan 
education. Thus, the role of extension is very important to support sustainable agriculture which is moving from production to a wider set of sustainability (Salem, 1994). Proper management of information sets a foundation for the delivery of efficient and effective extension services by providing accurate information to those who need it, when they need it. Therefore, identifying extension organizational characteristics of supporting agriculture is one of the major approaches needs to be carefully thought and accurately implemented for the extension system development. Also, measuring attitudes of farmers towards the extension services they receive is crucial in providing sustainable agricultural extension services. Another important issues include increase in farmer participation in sustainable agricultural development programs and agricultural extension services, decentralizing from activities and facilitating to apply local groups are the most important approaches for Agricultural extension in future (Allahyari, 2009). Financial, social, human and organizational sustainability should be achieved over time and policies that provide affordable access to information need to be carefully identified and examined (Hosseini et al., 2009).

Agricultural extension was once known as the application of scientific research and new knowledge to agricultural practices through farmer education. The field of extension now encompasses a wider range of communication and learning activities organized by professionals from different disciplines (Saville, 1965).

Extension agents receive regular training to enhance their technical skills, which they then hope will pass to all farmers through regular communication with small numbers of selected contact farmers. But the contact farmers are usually selected on the basis of literacy, wealth, readiness to change and "progressiveness," and so this sets them apart from the rest of the community. The secondary transfer of the technical messages, from contact farmers to community, has been much less successful than predicted and adoption rates are commonly very low among noncontact farmers. Without a doubt, $\mathrm{T}$ and $\mathrm{V}$ is now widely considered as ineffective (Antholt, 1994; Hussain et al., 1994).

Extension need to involve farmers themselves in the process of extension. Participation if it is to become part of extension must clearly be interactive and empowering. Any pretence to participation will result in little change. Allowing farmers just to come to meetings or letting a few representatives sit on committees will be insufficient (Antholt, 1994).

The Agricultural Extension System (AES) can be defined as an agricultural information exchange system which shows the actors, people and institutions, their interactions and communication networks between these actors to coordinate the information related processes (Demiryurek, 1999). The focus on the farmers' skills and education in any AES is the most important role for extension systems for accomplishment of dimensions and policies of Sustainable agricultural development. The development and implementation of sustainable agricultural practices require active involvement, by research centers and Private sector organizations and agricultural organizations and agricultural extension management in Extension Methods for creating awareness among the farmers about improved agricultural technologies (Chaudhry et al., 2006).

Agricultural extension methods and organizational characteristics encompass a diverse range of socially sanctioned and legitimate activities which seek to enlarge and improve the abilities of farmers to adopt more appropriate and often new practices and to adjust to changing conditions and societal needs (Swanson et al., 1997).

The Agricultural Extension management organizes to put up posters along the main roads where farmers can easily see them and broadcasting the agricultural information through the television and radio in the agricultural section. The agricultural newsletters and pamphlets are distributed to farmers during the seasonal crop production periods (Cho and Boland, 2004).

Many factors contribute towards the development of agriculture, including extension as an institutional input. Agricultural technologies and techniques are constantly changing and farmers need to be made aware of and know how to use agricultural innovations for the exploitation of inherent yield potentials. Worldwide the public sector plays a dominant role in the provision of agricultural extension and services (Axinn and Thorat, 1972; Lees, 1991; Swanson et al., 1997).

Performance of extension agents is expected to increase if they have program development competencies and to keep extension agents competent and to further improve their performance, these competencies must be considered and upgraded and continuous assessment of extension agents' competencies and performance is recommended (Tiraieyari et al., 2010). The effectiveness of extension services is also highly dependent on the ability of extension workers who are competent as the whole extension process is dependent on them to transfer information from extension organizations to the clients. 


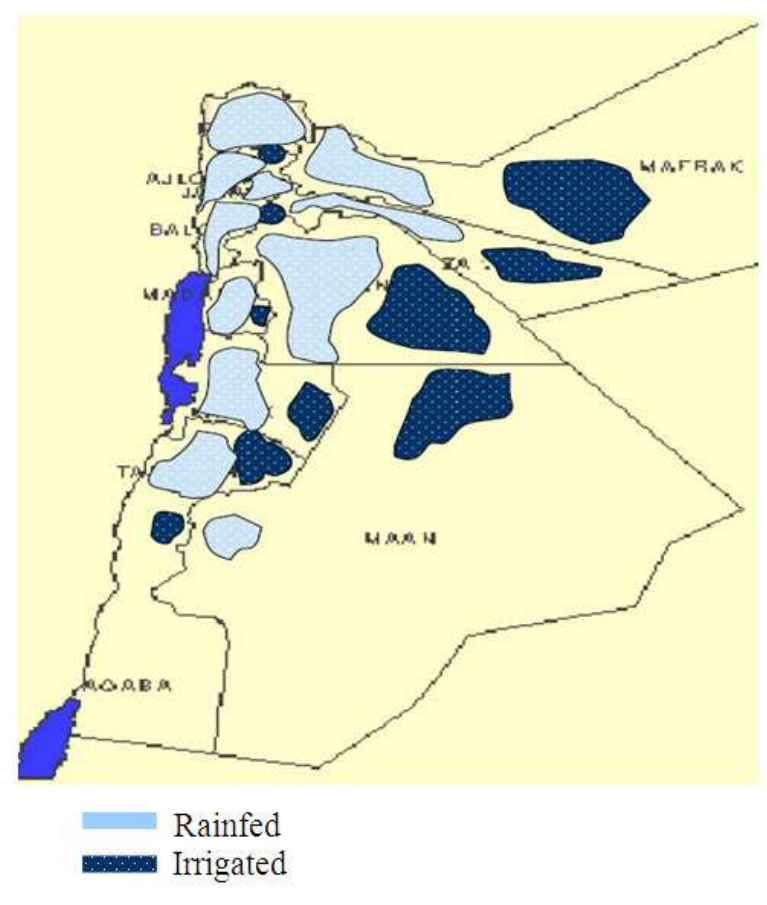

Fig.1: Olive producing regions in Jordan, Source: AlShdiefat et al. (2006)

However, serious reservations are being expressed about the performance and capability of this sector, placing the future of the public extension system in doubt. Rivera and Schram (1987), for example, argues that the performance of public agricultural extension in developing countries has been disappointing and has failed to transfer agricultural technology to the farmers. Furthermore, large numbers of farmers remain outside the ambit of extension providers (Schwartz, 1994).

The main objective of this study is to assess effectiveness of Jordan's agricultural extension services.

Effectiveness of agricultural extension activities: FAOUN (1984) stated that: "Effective extension work requires management and operational procedures that reinforce the organizational structure. These must contribute to a favorable work environment and result in systematic and expeditious handling of the many administrative tasks of the organization. Inadequacies in any of these areas can seriously impair the performance of an extension service". Mott (1972) defined 'effectiveness' as the ability of the organization to be mobilized to meet the demands in the areas of production, adaptability and flexibility. According to Etzioni (1964), the actual effectiveness of a specific organization is determined by the degree to which it realizes its goals.
In the light of the above definitions, the researchers in this study conceptualized the meaning of effectiveness as the ability of agricultural extension services to mobilize their capacity to meet the demands of the women farmers in the area of agricultural production.

Olive Production in Jordan: A brief review: Jordan was considered the tenth producing country in the world in 2001, while Syria ranked as the fourth producing country, Tunisia comes next to Syria. There are two main olive producing regions in Jordan; the western mountain ranges that cross the country from north to south and the north eastern desert region (Fig. 1 ). The former is rain-fed, while the latter is irrigated (MOA, 2009). According to MOA (2009) figurs, there are around 17 million olive trees in Jordan, generating a yearly income of JD100 million, with an average export worth JD20 million per year. Olive tree is the most important fruit tree grown in Jordan. It covers about $72 \%$ of the total area planted with fruit trees and about $36 \%$ of the total cultivated area (MOA, 2009). The Jordanian Department of Statistics (DOS) report (2009) showed that the country's total olive production increased by $30 \%$ last year, reaching 171036 tons compared with 94,000 tons in 2008 . Of which $69 \%$, or 142242 tons, was used for extraction of oil. The northern Governorate of Irbid registered the highest production of olive oil last year with 3429 tons, followed by Jerash and Ajloun with 2656 and 2576 tons respectively. Large numbers of olive farms belong to small and medium-size holders which are considered as a source of income for thousands of Jordanian families and provide many seasonal job opportunities for agricultural workers.

\section{MATERIALS AND METHODS}

Instruments for data collection: To collect primary data, two interview-cum-structured questionnaires were designed and used to collect information and data for this study. The first instrument was designed for farmers who received extension services and the second for farmers who received no extension services. Another questionnaire was designed for administrators of extension organizations concerned with providing extension services to farmers. The survey questionnaires included the following main sections:

- The importance of extension services to the farmers

- The effects of extension services on farm productivity and farmers' income and other socioeconomic aspects 
Am. J. Agri. \& Biol. Sci., 7 (2): 194-200, 2012

- The types of extension methods that are commonly used by extension personnel in providing advice to farmers

- The sources of extension services

The questionnaires were tested before conducting the final surveys. Twenty personnel and twenty farmers in the study area were selected for pre-testing. Necessary modifications were made before proceeding to the final surveys. The data were collected in two phases. In the first phase, farmers were interviewed, either in groups or individually, using the structured questionnaire. In the second phase, field extension agents and related extension organizations personnel were interviewed. The two phases included collecting data and/or information on how the agricultural extension systems actually influenced the operation of extension work for satisfying the problems and needs of farmers.

Secondary data were collected from its related sources. The Ministry of Agriculture (MOA), Jerash Agricultural Directorate, The National Center for Agricultural Research and Extension (NCARE) and many published studies were the main sources. The data were collected during the last five months of the year 2009 by the help of a three well trained agricultural engineers specialized in Plant Production and a well structured and validated interview schedule. The data obtained from the study area were organized in two groups according to farmers benefit or not from the extension services. The groups were classified as experimental and control. The experimental group was categorized according to the source of the provided extension service. Three effective sources of agricultural extension services were considered in this study, they are; MOA, NCARE and Private Sector.

The sample: A total number of 60 olive producers were selected to be interviewed for this study. This number is enough to achieve the study objectives. It represents more than $15 \%$ of the total olive farmers in the whole governorate. The interviewed producers were distributed almost equally within olive production locations in study area. The sample obtained through simple random sampling technique. Two groups have been chosen and distributed randomly into experimental group (30 farmers; 10 for each source of extension service) and control group (30 farmers). The experimental group received extension services and the control group received no extension services. The design of the study is shown in Table 1 and the distribution of the experimental group according to the source of extension services is shown in Table 2.
Table 1: The design of the study

\begin{tabular}{lll}
\hline Group & Number & Procedure \\
\hline Experimental & 30 & Received extension services \\
Control & 30 & Received no extension services \\
Total & 60 & \\
\hline
\end{tabular}

Source: Prepared by the researchers

Table 2: The distribution of the experimental group according to the source of extension services

\begin{tabular}{ll}
\hline Source of extension service & No. of producers \\
\hline MOA & 10 \\
NCARE & 10 \\
Private Sector & 10 \\
Total & 30 \\
\hline
\end{tabular}

Source: Prepared by the researchers

Study area: This study was conducted in Jerash governorate. Jerash governorate is one of the rainfed areas that have had olive cultivations since hundreds of years. It accounts of about $9 \%$ of the olive cultivation, $12 \%$ of olive production and $12 \%$ of olive oil production in Jordan. The total cultivated area with olive trees in Jerash is about 61245 Dunums (1 Dunum $\left.=1000 \mathrm{~m}^{2}\right)$, in which 781962 olive bearing trees were planted, with an average production of $15 \mathrm{~kg} /$ tree annually. The total olive production of the governorate is 11620 tons (MOA, 2009). Olive farmers in Jerash governorate were selected to represent the population of the study. It is one of the most important olive production areas in Jordan. Production conditions in Jerash resembles production conditions in any part of the country, including olives species, quantity of production, quality of production, production needs and any other related issue.

Analysis of data: Data from questionnaires were coded. A wide variety of data was summarized and categorized in different ways for ease of presentation and comprehension. The Statistical Package for Social Sciences software (SPSS) was used in the analysis process. To find the differences that may exist between the two studied groups, One Way Analysis of Variance (ANOVA), t-test and LSD test were used. They are powerful and common statistical procedures in analysis. They are used to test hypotheses about differences between two or more means. In their simplest form, ANOVA, T-test and LSD provide a statistical test of whether or not the means of two or more groups are equal.

The average net profit obtained from an area of one dunum of olive farm was the main item to be considered in determining the effectiveness of agricultural extension activities.

\section{RESULTS}

Effectiveness of Agricultural extension services in Jordan is consequently compromised. 
Table 3: Descriptive analysis and mean comparisons for both the experimental and control groups

\begin{tabular}{|c|c|c|c|c|c|c|}
\hline \multirow[b]{2}{*}{ Group } & \multirow[b]{2}{*}{$\mathrm{N}$} & \multirow[b]{2}{*}{ Mean } & \multirow[b]{2}{*}{ SD* } & \multicolumn{3}{|c|}{0.95 Confidence Interval for Mean } \\
\hline & & & & Lower bo & ound & Upper bound \\
\hline Experimental & 30 & 88.50 & 27.46 & 45 & & 142.50 \\
\hline Control & 30 & 87.50 & 39.30 & 15 & & 157.50 \\
\hline Total & 60 & 87.75 & 33.66 & 15 & & 157.50 \\
\hline \multicolumn{7}{|c|}{ SD*: Standard Deviation } \\
\hline \multicolumn{7}{|c|}{ Table 4: Results of t-test } \\
\hline Group & $\mathrm{N}$ & Mean & SD* & Mean SD** & T value & Sig. (2-tailed) \\
\hline Experimental & 30 & 88.50 & 27.46 & 5.01 & 0.171 & 0.865 \\
\hline Control & 30 & 87.50 & 39.30 & 7.18 & ---- & ----- \\
\hline Total & 60 & 87.75 & 33.66 & ----- & ---- & ----- \\
\hline \multicolumn{7}{|c|}{ SD*: Standard Deviation; SD**: Standard Error } \\
\hline \multicolumn{7}{|c|}{ Table 5: Multiple Comparisons (LSD Test) } \\
\hline \multicolumn{2}{|c|}{ Source } & \multicolumn{4}{|c|}{ Comparison } & Sig.(2-tailed) \\
\hline \multirow{2}{*}{\multicolumn{2}{|c|}{ MOA }} & \multirow{2}{*}{\multicolumn{4}{|c|}{$\begin{array}{l}\text { NCARE } \\
\text { Private Sector }\end{array}$}} & 0.044 \\
\hline & & & & & & 0.021 \\
\hline \multirow{2}{*}{\multicolumn{2}{|c|}{ NCARE }} & \multicolumn{4}{|c|}{ MOA } & 0.044 \\
\hline & & \multicolumn{4}{|c|}{ Private Sector } & 0.743 \\
\hline \multirow{2}{*}{\multicolumn{2}{|c|}{ Private Sector }} & \multicolumn{4}{|c|}{ MOA } & 0.021 \\
\hline & & \multicolumn{4}{|c|}{ NCARE } & 0.743 \\
\hline
\end{tabular}

This presents a problem in terms of the continuing support required by farmers in order to fully realize the development potential from improved land and water resources (IFAD, 2004). The effectiveness of agricultural extension activities in Jordan was investigated in this study. Table 3 shows the results of the descriptive analysis and mean comparison for both the experimental and control groups.

Table 4 shows the results of $\mathrm{T}$ test used to see if there were any significant differences between the two groups with regard to their results on the mean comparison at the $\mathrm{p}<0.05$ level. this test.

Table 5 shows the results of Least Significance Test (LSD) used to compare differences between all pairs of means.

\section{DISCUSSION}

Table 3 showed that the means of the net profits for the experimental group and the control group were 88.5 and 87.5 respectively. The standard deviations were 27.46 and 39.3 respectively. The values of the standard deviation for both the experimental and control groups show that the variation or "dispersion" of both groups from the average or the mean grade is not identical. The lower bound for the experimental group was 45 while the upper bound for the same group was 142.5. For the control group the lower bound was 15 while the upper bound was 157.5.

The results revealed that both groups are almost the same in the level of net profit per dunum.
Table 4 showed no significant difference between the experimental and control groups $(t=0.171$, $\mathrm{p}<0.05$ ). The results drawn form the t-test show that the experimental group achieved nearly the same level of net profit per dunum. The value of the significance for equality of means for the t-test was more than 0.05 which is 0.865 . These results seem to indicate that the net profit of the farmers who received extension services was almost the same as those who did not received any extension services. These results indicated that the provided extension services made no difference in the achievement of farmers regarding their production and consequently their net profits. These results confirm both IFAD (2004) and USAID (2005) results about weakness of the agricultural extension services in Jordan. These results may be attributed to the fact that MOA extension staff lacked competency, rarely visited farms and distributed limited and outdated information. MOA provides inadequate service, because its extension personnel are not well enough informed on up-to-date technologies and do not have adequate facilities, in particular, transportation to visit farms.

As shown in Table 5 the LSD post-hoc comparison showed that number of means were significantly different, $p<0.05$ (2-tailed). The table showed that there were significant differences between MOA as a source of extension services and NCARE in favor of NCARE. The value of significances for equality of means for the two sources was 0.044 which is less than 0.05 . Also, the LSD test revealed significant differences between the mean profits of MOA and Private Sector, the significance value was 0.021 in favor of the Private Sector. The mean profits of the other types of sources show no significant differences between them.

According to these results and the data analyses, the most effective source in providing the extension services was the Private Sector with a mean profit per dunum of 99 JDs. The least effective source was the MOA with a mean profit per dunum of 71.25 JDs. The NCARE was in intermediate position with a mean profit per dunum of 89.50 JDs. The private sector is a more reliable source in providing extension services. Private sector extension services are strong in input supply for many areas of plant production. Olive production is one of these areas. Its extension agents have direct and frequent contact with farmers. NCARE is driven more by academic study than by solving production constraints experienced by farmers. Applied NCARE research activities have permitted limited amounts of technology transfer through written publications, field days for farmers and on farm trials 
(USAID, 2005). This is true and the limited role of NCARE in providing a reliable extension services confirm this fact. The findings of this study agree with the above mentioned statement by USAID.

\section{CONCLUSION}

The net profit of the farmers who received extension services was almost the same as those who did not received any extension services. The provided extension services made no difference in the achievement of farmers regarding their production and consequently their net profits. These results confirm both IFAD (2004) and USAID (2005) results about weakness of the agricultural extension services in Jordan. The most effective source in providing the extension services was the private sector and the least effective source was the MOA. The NCARE was in intermediate position.

Recommendations: To overcome most of the previous obstacles, extension programs in Jordan must adopt innovative and efficient management techniques and qualified managers to remain high performers. They must improve their personal, team and cultural management skills in the field of agricultural extension activities. Government should impart extensive inservice agricultural trainings to train the extension personnel to cope with the growing needs of farmers. Government also, should impart trainings and refresher courses to train the Extension Field Staff (EFS) about the philosophy and methodology of extension services. Effective and efficient evaluation mechanism should be launched to monitor and evaluate the activities of EFS and their performance. Service structure for agriculture extension departments should be revised like other departments so that efforts will be made to reduce overlap in the extension mandates of the multiple institutions involved. The formation of a public-private sector to ensure that agricultural extension reaches all farmers, not just the large scale, commercial producers. The establishment of field demonstration sites, pilot sites on farmers' fields around the demonstrations and the training of MOA extension agents. Government should take a quick and serious step to take on maximum number of agricultural extension professional in the Agriculture Department (extension wing) and also designed a proper policy for it.

Most of these recommendations could be found in the United States Agency for International Development (USAID) assessment report (2005).

\section{REFERENCES}

Allahyari, M.S., 2009. Agricultural sustainability: Implications for extension systems. Afr. J. Agric. Res., 4: 781-786.

Al-Shdiefat, S., M.S. El-Habbab and A. Al-Sha'er, 2006. Introducing organic farming system in olive production and linking small farmers to markets: "A Success Story". Ministry of Agriculture, Annual Agricultural Statistics. Amman, Jordan.

Antholt, C.H., 1994. Getting Ready for the TwentyFirst Century: Technical Change and Institutional Modernization in Agriculture. 1st Edn., World Bank Publications, Washington, D.C., ISBN: 0821325108, pp: 46.

Axinn, G.H. and S. Thorat, 1972. Modernizing World Agriculture: A Comparative Study of Agricultural Extension Education Systems. 1st Edn., Praeger, New York, pp: 216.

Chaudhry, K.M., S. Muhammad and I. Ashraf, 2006. Alternative extension approaches to technology dissemination for sustainable agriculture in the Punjab, Pakistan. Int. J. Agric. Biol., 8: 836-839.

Cho, K.M. and H. Boland, 2004. Education and extension for multi-functional agriculture. AIAEE. Dublin, Ireland.

Demiryurek, K., 1999. The Analysis of Information Systems for Organic and Conventional Hazelnut Producers in Three Villages of the Black Sea Region, Turkey. 1st Edn., University of Reading, UK., pp: 744.

Etzioni, A., 1964. Modern Organizations. 1st Edn., Prentice Hall of India, Englewood Cliffs, NJ., pp: 120.

FAOUN, 1984. Extension - a Reference Manual. 2nd Edn., Food and Agriculture Organization of the United Nations, Rome, pp: 200.

Hosseini, S.J.F., M. Niknami and G.H.H. Nejad, 2009. Policies affect the application of information and communication technologies by agricultural extension service. Am. J. Applied Sci., 6: 14781483. DOI: $10.3844 /$ ajassp.2009.1478.1483

Hussain, S.S., D. Byerlee and P.W. Heisey, 1994. Impacts of the training and visit extension system on farmers' knowledge and adoption of technology: Evidence from Pakistan. Agric. Econo., 10: 39-47. DOI: 10.1016/0169-5150(94)90038-8

IFAD, 2004. Document of the International Fund for Agricultural Development. Upper East Region Land Conservation and Smallholder Rehabilitation Project, Interim Evaluation. Jordan. 
Jamilah, O., M. S.H. Azril, U. Jegak, M. Asiah and A.N. Azman et al., 2010. Can quality of work life affect work performance among government agriculture extension officers? A case from Malaysia. J. Soc. Sci., 6: 64-73. DOI: 10.3844/jssp.2010.64.73

Lees, J.W., 1991. More Than Accountability: Evaluating Agricultural Extension Programs. 1st Edn., The Rural Development Centre, University of New England, Armidale, ISBN: 0858349019, pp: 145 .

MOA, 2009. Annual agricultural statistics. Ministry of Agriculture Amman, Jordan.

Mott, P.E., 1972. The Characteristics of Effective Organizations. 1st Edn., Harper and Row, New York ISBN: 0060446358, pp: 227.

Rivera, W.M. and S.G. Schram, 1987. Agricultural Extension Worldwide: Issues, Practices and Emerging Priorities. 1st Edn., Croom Helm, London, ISBN: 0709942389, pp: 294.

Rivera, W.M., E.M. Elshafie and K.H. Aboul-Seoud, 1997. The public sector agricultural extension system in Egypt: A pluralistic complex in transition. J. Int. Agric. Extension Educ., 9: 67-74.

Sallam, M.S., 1994. Expectations from farmers in mediterranean southern countries: The case of Egypt. J. Cahiers Options Mediterranean's, 2: 119122.
Saville, A.H., 1965. Extension in rural communities: A Manual for agricultural and home extension technician workers. Oxford University Press.

Schwartz, L.A., 1994. The role of the private sector in agricultural extension: Economic analysis and case studies. Cornell University, USA.

Sinkaiye, T., 2005. Agricultural Extension Participatory Methodologies and Approaches in Agricultural Extension in Nigeria. AESON, Ilorin.

Swanson, B.E., R.P. Bentz and A.J. Sofranko, 1997. Improving Agricultural Extension: A Reference Manual. 3rd Edn., FAO, Rome, ISBN: 9251040079, pp: 220.

Tiraieyari, N., K. Idris, J. Uli and A. Hamzah, 2010. Competencies influencing extension workers' job performance in relation to the good agricultural practices in Malaysia. Am. J. Applied Sci., 7: 1379-1386. DOI: 10.3844/ajassp.2010.1379.1386

USAID, 2005. Assessment of agricultural extension services in Jordan valley and Amman-Zarqa basin highlands in Jordan. United States Agency for International Development, The Academy for Educational Development, Amman, Jordan. 